\title{
Subalternidade nas sociologias brasileira e indiana: um estudo comparativo da obra de Jessé Souza e Gayatri Spivak
}

\author{
Fabio Alves Ferreira ${ }^{1}$ \\ Universidade de Pernambuco
}

Resumo: As sociedades brasileira e indiana são muito desiguais. Ambos os países não constroem igualmente uma cidadania para todos. Para Jessé Souza é preciso criticar a ciência brasileira pois ela foi a responsável por manter este tema invisível na literatura. Gayatri C. Spivak também concorda que a desigualdade é mantida epistemologicamente e culturalmente, além do econômico. Assim, emergem grupos e classes sociais subalternizadas. Para ambos é preciso criar condições institucionais que assegurem o reconhecimento e a plena cidadania para todas as classes sociais e/ou grupos subalternos.

Palavras-chave: subalternidade; desigualdade; Brasil; Índia.

${ }^{1}$ Professor adjunto da UPE. Doutor em Sociologia pela Universidade Federal de Pernambuco. Mestre em Ciências da Religião com concentração em Ciências Sociais e Religião pela Universidade Metodista de São Paulo (UMESP). Graduado em Ciências Sociais pela Universidade Federal Rural de Pernambuco e em Teologia também pela UMESP. 


\title{
Subalternity in Brazilian and Indian sociologies: a comparative study of the work of Jessé Souza and Gayatri Spivak
}

\begin{abstract}
Brazilian and Indian societies are very unequal. Both countries do not build equal citizenship for all. For Jessé Souza, it is necessary to criticize Brazilian science because it was responsible for keeping this theme invisible in the literature. Spivak also agrees that inequality is maintained epistemologically and culturally as well as economically. Thus, subordinate groups and social classes emerge. Both must create institutional conditions that ensure recognition and full citizenship for all social classes and/or subordinate groups.
\end{abstract}

Keywords: subalternity; inequality; Brazil; India.

\section{Subalternidad en sociologías brasileña e indiana: un estudio comparativo del trabajo de Jessé Souza y Gayatri Spivak}

\begin{abstract}
Resumen: Las sociedades brasileña e india son muy desiguales. Ambos países no construyen la ciudadanía para todos por igual. Para Jessé Souza, es necesario criticar la ciencia brasileña porque ella fue la responsable de mantener este tema invisible en la literatura. Gayatri C. Spivak también coincide en que la desigualdad se mantiene epistemológica y cultural, además de la económica. Así surgen grupos subalternizados y clases sociales. Para ambos, es necesario crear condiciones institucionales que aseguren el reconocimiento y la ciudadanía plena de todas las clases sociales y/o grupos subordinados.
\end{abstract}

Palabras clave: subalternidad; desigualdad; Brasil; India. 
$\mathrm{U}$ ma marca fulcral das sociedades contemporâneas é a desigualdade intensificada. Esta questão social é agravada intensamente pelo modo de organização capitalista hegemônico no mundo. O capitalismo, não é novidade, implica na concentração de riqueza por uma parte pequena da população, que por sua vez está em alguns poucos países do globo. Desta maneira, uma linha geográfica torna-se possível na cartografia da pobreza: de um lado os países do Sul Global e de outro os países do Norte Global. Contudo, não é possível falar de uma desigualdade produzida somente pelo eixo econômico. Nem de longe pretendemos subestimar esta máquina de injustiça, porém não podemos deixar de enfatizar que a situação é ainda mais complexa.

A subalternidade a que nos referimos é também de ordem cultural, linguística, social e está enviesada na educação, na arte, na literatura, etc. Ela calhou no mundo pelo imperialismo colonialista e perdura em termos epistemológicos além do econômico. Este artigo busca compreender como estas formas de produzir diferença são retratadas nos estudos críticos de Jessé Souza e Gayatri Chakrovorty Spivak. Aqui no Brasil, por meio de uma crítica das narrativas hegemônicas. E na Índia, pela crítica da cultura. Os dois autores ligam as várias faces da desigualdade aos projetos colonialistas que ambos os países foram submetidos.

Mais especificamente, nosso objetivo é o de analisar em profundidade as obras de Jessé Souza e Gayatri Spivak, delineando o conceito de subalternidade para compreensão das desigualdades presentes nas sociedades brasileira e indiana. Também prestaremos atenção em como a repetição de discursos hegemônicos foram necessários para a naturalização de uma cultura de dominação. Ambos os autores desnaturalizam a desigualdade e evidenciam os mecanismos utilizados para o processo de permanência da mesma.

Jessé Souza é um sociólogo brasileiro e professor universitário. Ele foi presidente do Instituto de Pesquisas Econômicas Aplicada (IPEA), órgão a partir do qual o Governo Federal baliza suas políticas públicas. Também desenvolveu estudos de aprofundamento da cultura brasileira e questionou os clássicos intérpretes das transformações históricas do Brasil. Segundo ele, há uma narrativa que perdura no pensamento social brasileiro que foge a uma característica de realidade. Refere-se à construção da ideia de uma identidade brasileira malandra, festeira e corrupta. Esta concepção além de naturalizar o país como atrasado, aponta que o patrimonialismo é o principal problema do Brasil. Ideias presentes, segundo sua análise, em autores como Gilberto Freyre, Raymundo Faoro, Sérgio Buarque de Holanda, Fernando Henrique Cardoso, Roberto DaMatta e outros (SOUZA, 2000, 2015).

Jessé Souza explora o quanto estas narrativas construíram um simulacro que atualizava o Estado como malfeitor e o Mercado como redentor. Servindo, portanto, à ignorância desejada pelo mercado acerca da desigualdade crônica na sociedade brasileira. Segundo ele, temos aqui no Brasil quatro classes sociais, sendo a mais afetada a Ralé Brasileira. Esta classe é composta por 40\% da população e dela fazem parte grupos sociais sem capital financeiro e muito menos capital cultural para provocar a sua mobilidade social. (2009, 2010, 2006a, 2006b).

De outro lado, igualmente no Sul global, mas em outro continente, temos Gayatri Chakravorty Spivak e os estudos de Subalternidade na Índia. Spivak explora 
a subalternidade como um modo de colonização e que foi sedimentada na cultura. Para ela, os subalternos são atores invisíveis, sem voz, sem possibilidade de transformação social. Aqueles cuja fala não produz nenhum efeito social. Ignorados em seus lugares sociais por uma estrutura rígida que os enclausuram.

Gayatri Spivak resgata Antonio Gramsci para dizer que o subalterno consiste naqueles grupos de sujeitos proletariados, excluídos pelas formas desiguais em que se instalam o mercado, a representação política e até mesmo a distribuição do capital cultural. Neste sentido, aos subalternos é legada a representação de que devem assumir posições sociais de inferioridade (1998, 2006, 2008, 2010).

Estes elementos, até aqui levantados, já são suficientes para percebermos que há grupos impedidos estruturalmente de provocar sua mobilidade social. Podemos perceber que os subalternos constituem categorias e grupos de gênero, identidade, classe, etnia, dentre outros. No decorrer deste texto vamos aprofundar essa gramática da desigualdade cultural, mais do ponto de vista teórico-analítico do que por meio de dados empíricos, muito embora as teorias levantadas destes autores foram resultantes de pesquisas históricas, literárias e, também, estatísticas. Este é o caso, principalmente, de Jessé Souza, cujas pesquisas envolveram milhares de pessoas em regiões diversas do Brasil, tendo assim um amplo alcance. Com esse aporte, sinalizaremos possíveis caminhos de emancipação a partir da leitura em profundidade da teoria produzida por Jessé Souza. Já em Gayatri C. Spivak além de dimensionar o campo cultural nos empenharemos no sentido da categoria "subalternidade" que transparece em sua obra como elemento chave na explicitação da condição de vida dos indianos. A partir desta empreitada poderemos fomentar uma maior compreensão do povo brasileiro, as desigualdades de classe, as barreiras sociais e a necessidade de pensar sistematicamente os caminhos para superação desses dilemas.

A metodologia empregada foi a de pesquisa bibliográfica. Este recurso metodológico foi fundamental na compreensão das particularidades históricas e culturais das sociedades analisadas. As ciências sociais procuram compreender as diferenças dentro de contextos sociais e históricos amplos.

Ainda em tempo destacamos que é impossível, num artigo, realizar de forma justa uma explanação de ambos os autores aqui abordados. Eles têm extensas pesquisas e suas considerações renderam vários livros. Embora Jessé Souza seja bastante didático não é fácil selecionar suas ideias principais, visto que para compreendê-las é necessário realizar uma digressão histórica para situar a origem da estrutura desigual no Brasil. De outro aparte, Spivak é considerada densa em seus textos e quase nada de sua obra está traduzida para o português. ${ }^{2}$ Neste sentido, com o intuito de contribuir para uma introdução de ambos, nos esforçamos para construir um texto cuja dinâmica predominante na exposição seja a clareza na articulação das ideias. Esperamos, finalmente, ser eficientes na exposição do pensamento destes dois críticos do capitalismo contemporâneo.

2 Os exemplos abordados neste artigo foram extraídos do livro "Pode o subalterno falar?". Ampliamos esta leitura para os argumentos encontrados nos textos de língua inglesa e, também, gastamos horas aprendendo com suas palestras disponíveis na plataforma Youtube e devidamente referenciadas na bibliografia final. 


\section{Subalternidade: o que é isso?}

Desde já é preciso conceituar subalternidade como categoria que apresenta elementos externos ao indivíduo. Isso ultrapassa bases subjetivas de definição. Além disso, peremptoriamente classifica este lugar social como espaço político fundante do ser. Então, o que é subalternidade? Sem aprofundar numa historiografia do conceito, uma vez que não consiste como objetivo deste trabalho, o termo foi amplamente explorado por Antonio Gramsci $(1978,2002)$ e estava estritamente relacionado à sua concepção de hegemonia.

Deste modo, subalternidade implicava em reconhecer a necessidade de posturas políticas que pudessem subverter os males decorrentes da condição desigual de classe e de política também. Alterar a condição subalterna é produzir saberes e posições contra hegemônicas (SEMIONATTO, 2010). Tanto Spivak quanto Souza (2010) justificam a perspectiva de superação da condição de colônia moderna pelo reconhecimento do imperialismo e pela sedimentação na cultura. Nestes campos estão atores cujas funções são sempre políticas. A maior ou menor possibilidade de atuar e provocar representatividade são localizados a partir da valorização cultural daquele que fala, de seu poder econômico, dos efeitos do imperialismo europeu. O recorte político passa pela observação atenta destas estruturas coloniais de verdade e evolução.

Atualmente, no pensamento social, o termo está relacionado à ausência de agência (SAID, 2007, 2011; SPIVAK, 2010). Desde aí, é que tem sido amplamente estudado no feminismo e nos estudos culturais também. Via de regra, uma premissa dos movimentos sociais contemporâneos é a de que a sua possibilidade de agência e alteração de seu contexto imediato, ganha potência no encontro com outros subalternos conscientes dessa posição social precária.

São, desta forma, assim como assinala Spivak (2010), Homi Bhabha (2010) e Boaventura Sousa Santos (2002), subalternizadas por vetores múltiplos. Os grupos subalternos carregam as seguintes características: (i) são sujeitos emudecidos epistemologicamente uma vez que seu saber sobre o mundo é desacreditado; (ii) vivenciam empiricamente a ausência de condições habilitadoras em sua formação (educação, família estruturada). Isto é, as instituições não operacionalizaram a intervenção na vida destas pessoas de forma a garantir plena cidadania. Sim, segundo Jessé Souza (2000, 2003, 2004), os indivíduos são formados no interior das instituições e estas contribuem para formação de indivíduos confiantes em suas iniciativas, para formação de seus selfs; (iii) ausência de capital cultural para se posicionar frente às violências decorrentes da falta de instituições operantes em termos de cidadania ativa. Para isso avançamos na urgência de delinear que a subalternidade não é somente pouco estímulo econômico. Consiste em todas as faltas em que mais ou menos sua condição de ser humano é um objeto construído socialmente que serve a alguém, porém não teve escolhas nesta vivência servil. Não é capaz de agenciar escolhas. Uma privação de capacidades frente às demandas exigidas do mundo exterior (SPIVAK, 2010; SEN, 2010). 


\title{
A estrutura da desigualdade no Brasil contemporâneo: a crítica de Jessé Souza
}

Uma das premissas fundamentais da análise empreendida por Jessé Souza (2002, 2005, 2006, 2009, 2010, 2013, 2018) é a de que o pensamento social brasileiro foi constituído com base em mitos. Foi isso que criou a ideia de que somos um povo "animado", com características emotivas em suas ações tanto no campo privado, quanto na esfera pública. Pensando nisso Jessé Souza busca desfazer esses mitos funcionais no Brasil.

\begin{abstract}
Até hoje, a interpretação brasileira dominante sempre partiu da análise pretensamente "científica" de uma singularidade sociocultural brasileira - singularidade essa pensada em termos absolutos e supostamente incomparável com qualquer outra experiência humana no planeta. Existem dois graves enganos nesse tipo de procedimento. O primeiro é que se parte de um ponto obviamente ideológico, na medida em que é fabricado por interesses 'pragmáticos' de se construir uma narrativa de 'unidade nacional', como claro compromisso de se produzir uma fonte alternativa de solidariedade social entre grupos e classes em conflito latente. (SOUZA, 2011: 103)
\end{abstract}

A mudança, então, deve ser a emergência de uma crítica às ciências sociais, responsável por não dar visibilidade ao fato de que há uma desigualdade colonial ainda presente no Brasil. Pensando nisso, Souza (2010) coloca em prática seu esforço de dissecar a formação das classes sociais. Em sua perspectiva, O processo de intervenção nesta sociedade será mais eficaz quando voltado para diminuir as desigualdades sociais desta sociedade. Souza interpreta o Brasil como uma sociedade constituída de quatro classes sociais: a ralé, os batalhadores, a classe média e a elite.

Em síntese, a classe social, conforme Souza, consiste num conjunto de características que faz as pessoas se comportarem de modo semelhante. Neste caso, a família possui um papel fundamental, pois a socialização familiar é determinante para formular o que somos. Sobretudo, na primeira socialização em que o aprendizado se dá, muito mais do que pelas palavras, pela repetição dos comportamentos. Os outros referenciais na maioria dos casos é a mãe ou o pai, ou pessoas que representam este papel. Jessé Souza usa o conceito de habitus, desenvolvido por Pierre Bourdieu. Conforme Souza, "o habitus é um sistema de estruturas cognitivas e motivadoras, ou seja, um sistema de disposições duráveis inculcadas desde a mais tenra infância que pré-molda possibilidades e impossibilidades, oportunidades e proibições, liberdades e limites de acordo com as condições objetivas". (SOUZA, 2003: 43-4)

Além disso, no Brasil, as divisões sociais são frutos da escravidão. Esse contexto histórico foi decisivo para posicionar as classes sociais como descendentes de escravos ou como pessoas de família nobre. Com isso, o processo de colonização e a escravidão foram o que deram origem as classes sociais que vemos hoje.

Para ilustrar e situar a Ralé brasileira na divisão das classes, podemos partir da vertente de privilégios usufruídos pela família de classe média. A pesquisa empírica de Jessé Souza levou a seguinte assertiva sobre a classe média: esta tem o poder de capital que possibilita comprar o tempo livre de seus filhos, o que os possibilitam a só estudar e acumular o capital cultural importante. Tal especialização vai lhe possibilitar o fácil acesso ao mercado de trabalho, com os melhores cargos do mercado e do Estado. Segundo Jessé, a classe média no Brasil corresponde a $20 \%$ da população privilegiada, os outros quase $80 \%$ dos brasileiros não tem disponível condições públicas habilitadoras para ascender. A ralé fica abaixo desse campo de privilégios e é a classe mais subalterna do Brasil. 
Contudo, toda classe possui uma família, que em grande medida possibilitará ou inibirá sua ascensão por meio de características peculiares que são tidas como naturais. Como por exemplo o pensamento abstrato e a capacidade de concentração são ferramentas essenciais para o desenvolvimento intelectual do cidadão e isso possibilitará ou não, obter acúmulo de capital cultural (SOUZA, 2010).

O desenvolvimento da Ralé ocorre no mesmo contexto de socialização familiar, porém diferente da classe média, ela apresenta suas particularidades onde são transferidos conhecimentos mais objetivos de trabalho. Onde são passados saberes que não estão ligados a intelectualidade e sim ao trabalho manual. A transferência de saberes se limita à realidade local, onde a classe Ralé usa a força de trabalho como forma de subsistência, por ser carente de capacidades intelectuais necessárias para o ingresso em melhores empregos. Tal indivíduo da ralé chega ao mercado de trabalho como um analfabeto funcional. A estes indivíduos marcados definitivamente pela posição de classe resta a venda da força de trabalho literalmente. Há uma falta de incorporação do conhecimento e que é exigido pelo mercado capitalista.

Já a classe média usa a intelectualidade como atividade essencial de seu trabalho. Isso resulta na monopolização de recursos que irão ser concentrados nesta classe. Dessa forma, a ralé se encontra na base da pirâmide social e está sujeita a permanecer nela. Pois o sistema de organização social impede sua ascensão por subtrair suas ferramentas necessárias de representação social.

Já a classe os batalhadores são identificados por alguns serviços pertencentes ao mercado de trabalho. A terceirização de serviços na área de telemarketing é citada como trabalho típico da classe de batalhadores, pois é um meio precário de prestação de serviços; com baixos salários e com a falsa ideia de uso da intelectualidade para prestá-lo (SOUZA, 2010, 2005). Nesse caso o trabalho do telemarketing é usado para pessoas com qualificação mais baixa (ensino médio completo).

Estamos falando, neste caso, de um setor mais desprotegido da economia formal. Jornadas intensas, baixos salários, alta cobrança por produtividade. Nas pesquisas de Jessé Souza foi constatado que esse tipo de trabalho é executado por pessoas que possuem uma dupla jornada de trabalho e estudo, o que torna o trabalho mais exaustivo equiparado as atividades de pessoas que usam sua força de trabalho tal como os pedreiros. Dessa forma, pessoas que executam esse tipo de trabalho dificilmente conseguem ascender socialmente, pois a jornada exaustiva de trabalho arranca-lhe tempo para acumular capital cultural através do estudo. O cansaço físico é visto como uma preguiça própria por parte do trabalhador, levando a entender que o mesmo não se esforça o suficiente para alcançar seus objetivos. Quando na verdade é seu próprio corpo que o impossibilita de se dedicar a outras coisas por meio da exaustão de um dia cansativo.

Visto isso, essa classe de batalhadores tende a procurar alternativas que os possibilitem de evoluir dentro do sistema capitalista, o que leva muitos a desenvolver um espírito de empreendedor. Este estabelece trabalhos informais como por exemplo o trabalho de um camelô, que inicia seu emprego tendo como motivação a esperança de uma vida melhor. Jessé Souza em seu livro batalhadores brasileiros (2010) ilustra bem como seria essa tentativa de empreender no Brasil:

Seguindo sua ótica de fé e trabalho, alguns trabalhadores conquistavam mais sucesso, através de seu espírito empreendedor. Os batalhadores empreendedores acabam atingindo este maior êxito a partir apenas da experiência em trabalhos braçais e do conhecimento prático neles adquirido, gerando assim, microempreendimentos relativa- 
mente estáveis, caracterizando-se por uma visão estratégica do mercado que lhes permite acompanhá-lo na atualização da oferta dos serviços ou artigos que fabricam. (SOUZA, 2010: 203)

Partindo dessa tentativa de empreender, Jessé Souza relata as dificuldades subjetivas que essas pessoas tendem a enfrentar, visto que não possuem um capital suficiente para investir. $\mathrm{O}$ relacionamento de empréstimos com bancos $\mathrm{e}$ seus juros abusivos cria o efeito nefasto do "nome sujo" na vida do trabalhador, situação de humilhação extrema, de não ser confiável dentro do sistema econômico.

Portanto há uma diferença entre o batalhador e o cidadão de classe média. Essa classe, os batalhadores, não é uma classe média, pois a "linguagem de seu corpo" é diferente: "a nova classe trabalhadora não participa desse jogo de distinção que caracteriza as classes alta e média" (SOUZA, 2010: 49). O batalhador não busca a "conversão de capitais econômicos em culturais" (SOUZA, 2010: 238). A educação não tem valor intrínseco, mas tão somente instrumental. Enquanto a classe média esmera-se na tradução de capital cultural em capital econômico acumulativo. Trazendo uma concepção contrária por já possuírem o acúmulo de capital cultural.

As dificuldades estruturais impostas aos subalternos se apresentam de várias formas. Em grande parte, vêm disfarçadas e trajadas de legitimidade. Os aparelhos repressivos do Estado funcionam nessa direção. A figura da polícia militar se apresenta com grande frequência como mecanismo repressivo de pobres e a classe média por sua vez passa a aplaudir essas atitudes de repressão. Por alguns motivos e privilégios pertencentes a classe média, a mesma acha que faz parte da elite do Brasil. Jesse Souza, enfaticamente demonstra que esta classe é controlada pela elite, pois é ela que reproduz opiniões e ações da Elite. Assim, estes atores da classe média são fortalecidos com grandes cargos políticos.

Cada classe possui suas necessidades. A necessidade da elite é a apropriação de poder aquisitivo e a necessidade da classe média é justamente a de manter um status de privilégio, o que acarreta no ódio ao pobre. Por isso, há resistências culturais e até linguísticas na aceitação de uma sociedade mais equânime. Há uma luta de classe. No caso da classe média, não se preocupa com a evolução do país como um todo e sim em seu próprio desenvolvimento enquanto classe.

A limitação quanto ao acesso à educação é uma das formas que a classe média usa para monopolizar o conhecimento, pois a mesma sabe que por meio da educação a classe alcançará privilégios e prestígios que possibilitam a exploração das classes que não possuem esses poderes. Neste caso, à ralé restará apenas a posição social de servi-la com as necessidades de força de trabalho.

O estado como principal apaziguador das desigualdades não o faz, por estar diretamente ligado a essa elite que possui o poder de criar leis que legitimam a monopolização de recursos. $\mathrm{O}$ que perpetua a ação de uma única classe que consegue dominar os principais recursos políticos e econômicos de um país para lhes favorecerem.

Essa dificuldade que a classe ralé e a classe de batalhadores possuem para conseguir o poder aquisitivo do sistema capitalista, se dá por meio de todo um sistema implantado pela elite que legitima as desigualdades existentes e instaura um conceito de meritocracia, como se todas as classes tivessem a mesma oportunidade de se desenvolver frente ao sistema. Esse pensamento de que conquistar ou não conquistar algo no capitalismo se dá por meio de sua capacidade, faz com que o indivíduo se sinta culpado, passando apenas a enxergar a objetividade do 
espaço que ocupa e negando sua subjetividade que é o principal fator que lhe impede o desenvolvimento (2005, 2013).

Neste sentido temos que compreender o que realmente é a meritocracia defendida incisivamente pela classe média e a elite brasileira. A meritocracia surge no contexto liberalista, que é uma legitimação das desigualdades existentes. $\mathrm{O}$ liberalismo pensa a sociedade a partir do indivíduo isolado, ignorando as influências externas que determinam suas ações, tornando invisível os privilégios presentes em determinada classe, colocando as conquistas como um mérito individual.

Portanto o conceito de meritocracia em sua essência é a principal justificativa que a sociedade moderna capitalista possui para as pessoas que estão sendo oprimidas por ela. À medida que os indivíduos subalternos são fragmentados e não são reconhecidos como classe, são lhe atribuídos as mesmas potencialidades e dificuldades que a classe média e a classe elite possuem. O indivíduo é visto como principal responsável por sua riqueza ou pobreza. Sobre isso Souza coloca:

\begin{abstract}
E apenas porque as classes se tornam invisíveis é que o senso comum e, como veremos mais tarde, as "ciências" que se constroem a partir delas podem ver o indivíduo e o "mérito" individual como justificativa de todo tipo de privilégio. As classes sociais se reproduzem, portanto, de maneira duplamente invisível: primeiramente porque a construção das distintas capacidades de classe é realizada no refúgio dos lares e longe dos olhos do público; depois, invisível ao senso comum, que só atenta para o resultado, apresentado como "milagres do mérito individual", deixando as precondições sociais e familiares desse "milagre" cuidadosamente fora do debate público. (SOUZA, 2009: 47)
\end{abstract}

Sabemos então que no Brasil existem muitos fatores que descartam a ideia de uma meritocracia. O sistema meritocrático só seria possível se o Brasil possuísse condições iguais para as pessoas. Sobre isso, o arremate de Souza é conclusivo: seria necessária uma única escola para filhos de pessoas das mais distintas classes, com o mesmo poder de capacitação. Um único sistema de saúde para atender a todos como países realmente desenvolvidos.

Porém, contrariamente a este caminho, o Estado se apresenta como uma instituição "abrasileirada" onde a mesma possui características vistas como peculiares do povo brasileiro. Tal característica é descrita por Sérgio Buarque de Holanda (2014) como a figura do "homem cordial". O homem cordial seria um ser dotado de características que define todo o povo brasileiro. Seus valores morais estão diretamente ligados a suas emoções, por fazer a distinção entre amigos e inimigos, que serão favorecidos ou desfavorecidos conforme a afetividade de quem tem o poder de decidir sobre questões de interesse geral. Dessa forma não terá o fator de impessoalidade e de isonomia por meio da figura do Estado. Gerando a apropriação privada do público.

Para Jessé Souza (2009, 2013) essas características essencialistas atribuídas ao povo brasileiro se apresentam de forma explícita em demais países desenvolvidos, mas o povo passa a não enxergar essa apropriação do erário público realizada pelo patrimônio privado. Essa falsa concepção da realidade brasileira serve para legitimar as desigualdades e esconder os privilégios de determinadas classes. Sobre isso Souza afirma:

A tese do patrimonialismo permite defender privilégios, ou seja, ser uma "ideologia conservadora" de iniquidades, ao mesmo tempo em que dá a impressão de ser "crítica" da realidade. A meu ver é precisamente esse "golpe de mestre" de ter conseguido transformar uma ideia conservadora e que, na verdade, assegura a permanência de privilégios injustos, com a "aparência" de crítica social, o que explica, a despeito de sua fragilidade teórica evidente, a extraordinária longevidade e eficácia dessa ideia entre nós. (SOUZA, 2009: 69) 
O patrimonialismo nesse contexto cria um falso conflito entre o mercado e o Estado, pois ambos se necessitam para sua existência. Dessa forma, esse falso conflito tirará o foco dos reais conflitos que é o conflito de classes. É essa a hipótese de Souza, a de que o verdadeiro conflito é a luta de todas as classes em busca de recursos escassos. Visto que o Estado é o único ator social com a capacidade de amenizar as desigualdades sociais, o Estado também se torna útil para a classe média. Porém a única classe social na qual o Estado possui pouca influência é a elite do dinheiro que detêm poder sobre recursos escassos e sobre a mídia. Dessa forma a difamação do Estado é uma maneira eficiente de abrir espaço para a instauração do mercado.

No entanto, o interesse real em extirpar a corrupção é o mesmo de criar uma nova cultura política. Pois no modo em que a vida pública no Brasil é gerida, o Mercado é o corruptor do Estado. Isto ocorre por meio de monopólios de recursos que formam parcerias com o Estado e estabelecem a corrupção por desvio de verba pública para cofres privados, ou por meio de isenções fiscais que beneficiam grandes empresas privadas. Dessa forma o setor privado sempre se encontra presente nas mais variadas formas de corrupção do Estado.

Não só isso! Há uma série de ações do setor privado que barram a plena cidadania dos grupos subalternos. Um dos exemplos explorados por Souza é a fixação de altos preços em produtos e serviços e o alto índice de juros bancários que é visto como uma particularidade do Brasil. Este tipo de exploração legalizada está muito acima da média mundial de juros, chegando ao aumento de trezentos porcento sobre o real dinheiro adquirido pelo particular.

Dessa forma os banqueiros conseguem lavar dinheiro nacional por meio da taxa de juros abusiva e esse dinheiro é recolhido aos cofres de particulares, pois foi lhes dada essa autonomia. Isso configura o grande poder dessa classe que se sobressai entre as outras. É assim que a Elite consegue patrocinar a privatização de estatais. A privatização de estatais é o ato de pegar maior parte das riquezas nacionais e colocar em mãos de particulares, as mesmas que coordenam nossos bancos e lavam dinheiro por meio das taxas de juros (SOUZA, 2014, 2015, 2016).

Portanto, tendo como base esse contexto histórico peculiar do Brasil, Jessé Souza conclui que o Estado é a única instituição que possui o poder de regular as ações da classe elite brasileira por meio de medidas repressivas. Este acontecimento, entretanto, não se constitui em uma tarefa simples, visto que a elite possui o poder de comprar a política. Contudo a principal iniciativa para a amenização das desigualdades seria justamente a regulação do mercado no que se refere a exploração do povo.

Essa regularização do mercado se daria por meio de (i) políticas que envolveriam os grandes bancos do Brasil; e (ii) desfazendo do monopólio existente em poucas famílias brasileiras; (iii) regulando as taxas de juros existentes no Brasil; e (iv) cobrando taxas a pessoas que realmente tem condições de pagar, como grandes empresários. Outra medida cabível, seria (v) a formulação de políticas públicas que fornecessem às classes subalternizadas o poder de compra. Será através de políticas públicas concretas e aprofundadas que será possível às classes ralé e batalhadores se apropriarem do capital cultural, amenizando a exploração por meio da força de trabalho. Essa medida se torna relevante e perceptível à medida que a classe se apropria de capital financeiro e investe seu tempo para a apropriação de capital cultural, o que possibilitará sua ascensão enquanto classe.

Esta descolonização do Estado é urgente pois, na interpretação de Souza, a sociedade brasileira foi constituída sem um conceito essencial de igualdade. Portanto, isso criou o "contexto da modernidade periférica brasileira", com atributos 
de uma sociedade liberal onde predomina a desigualdade. Isso fez com que a sociedade brasileira fosse formada com a ideia de cidadania totalmente distorcida, ao ignorar classes sociais em seu processo de modernização.

\begin{abstract}
É essa 'dignidade', efetivamente compartilhada por classes que lograram homogeneizar a economia emocional de todos os seus membros numa medida significativa, que me parece ser o fundamento profundo do reconhecimento social infra e ultrajurídico, o qual por sua vez, permite a eficácia social da regra jurídica da igualdade e, portanto, da noção moderna de cidadania. É essa dimensão da 'dignidade' compartilhada, no sentido não jurídico de 'levar o outro em consideração', e que Taylor chama de respeito atitudinal, que tem que estar disseminada de forma efetiva em uma sociedade, para que possamos dizer que, nesta sociedade concreta, temos a dimensão jurídica da cidadania e da igualdade garantida pela lei. Para que haja eficácia legal da regra da igualdade é necessário que a percepção da igualdade na dimensão da vida cotidiana esteja efetivamente internalizada. (SOUZA, 2006: 166)
\end{abstract}

Com isso, é preciso subverter esta estrutura e produzir uma gramática do reconhecimento. A teoria do reconhecimento exposta por Jessé Souza, de modo geral, objetiva o reconhecimento das classes como subdivisões que possuem em sua essência o mesmo interesse, que é a melhoria da qualidade de vida. Para isso é necessário a apropriação de novos conceitos culturais, por meio de novas teorias que fujam das ideias liberalistas, unificando os objetivos das classes de modo geral. Essas verdades seriam implantadas por meio da literatura brasileira, em meios culturais, para que toda a sociedade compreenda nossa realidade e passe a questioná-la, levando pensamentos para além do senso comum, reconhecendo o Estado como capaz de amenizar as desigualdades sociais e controlando o mercado como formador das relações sociais e de capital, estabelecendo parâmetros de atuação e desconstruindo monopólios por meio de estímulos de setores mercantis.

\title{
Subalternidade e estrutura social: a crítica de Gayatri Spivak
}

A teórica literária indiana Gayatri Chakravorty Spivak é uma das intelectuais mais influentes quando falamos de pós colonialismo. Essa discussão gira em torno das consequências da colonização na maneira de pensar, que originaram os sujeitos subalternos, que são o nosso objeto de estudo. As análises e crítica da autora no ajudarão a lançar luz sobre como é constituída a subjetividade do sujeito subalterno.

A obra de Spivak, pode o subalterno falar? (2014), desenvolve a explanação em torno da agência do sujeito subalterno partindo da concepção da não existência de uma história verdadeira. Ou seja, considerar que só existe uma versão para um fato ocorrido é negligenciar todas as outras formas de ver esse mesmo fato sob perspectivas diferentes. Essa ideia de exposição passa a esconder muito mais do que mostrar os fatos, pois considerar uma história única é ignorar quaisquer outras histórias que existiram e existem concomitantes à oficial.

Neste sentido, Spivak assume o ponto de partida antiessencialista, uma vez que, para ela não existe na realidade social sujeitos únicos, puros ou livres de contaminações externas. Dessa forma a autora nega a possibilidade de um essencialismo do sujeito e da história, revelando o que até então era desconsiderado ou tratado com aspecto de inferioridade, que é escutar as narrativas de pessoas que compõem outra posição social e que vivenciam fenômenos de um mesmo contexto. 
Sendo assim, o sujeito subalterno é aquele que está presente nos acontecimentos sociais. É o responsável por outras narrativas para além das impostas institucionalmente. Porém, sua fala não é credível e isso o posiciona em situações marginalizadas. Deste modo, os grupos subalternos não são tratados como compostos de indivíduos intelectualmente capazes. Estes subalternos habitam "as camadas mais baixas da sociedade constituídas pelos modos específicos de exclusão dos mercados, exclusão da representação política e legal, e da possibilidade de se tornarem membros plenos no estrato social dominante" (SPIVAK, 2010: 14).

Essa concepção destaca um conceito que até então era pouco discutido, a ideia de um sujeito descentralizado e heterogêneo marcado pela sua localidade, temporalidade e sociabilidade. A partir deste pressuposto a autora faz uma crítica a intelectuais ocidentais, por ignorarem a possibilidade de a Europa não ser o centro de sua teoria. Essa crítica tem o objetivo de estimular o pensamento voltado às práticas de agenciamento do sujeito subalterno, localizados no Sul global.

A autora aborda o conceito de subalternidade em seu sentido amplo, porém em suas obras ela usa exemplos para ilustrar quem são esses sujeitos. Deste modo ela identifica algumas características compartilhadas por estes grupos: (i) socialmente não têm voz; e (ii) é um grupo heterogêneo e descentralizado. $\mathrm{O}$ argumento de Spivak é o de que o subalterno não está presente em literaturas, nem em obras filosóficas e sofre vários tipos de violências sociais explícitas e implícitas em seu cotidiano, o que o torna neutro em decisões políticas e mercantis, sem a possibilidade de ascensão social.

Para ilustrar e delimitar a condição de subalternidade presente na sociedade, Spivak cita a mulher como um exemplo claro de indivíduo subalterno, apresentando características peculiares de um sujeito duplamente calado. A autora afirma: "Se, no contexto da produção colonial, o sujeito subalterno não tem história e não pode falar, o sujeito subalterno feminino está ainda mais profundamente na obscuridade" (SPIVAK, 2010: 66-7).

Essa dupla inferioridade da mulher ocorre pelo fato dela ser mulher. Mesmo ela tendo a possibilidade de ascensão financeira ela sempre será vista como inferior ao homem por meio de uma cultura que foi naturalizada na sociedade póscolonial. Por isso, o exemplo do ser mulher é usada pela pesquisadora como uma pessoa que preenche todos os requisitos de indivíduo subalterno, pois ela é limitada simplesmente por sua condição de gênero.

Portanto o sujeito subalterno é todo o indivíduo que tem sua voz calada e que sofre violências em seu cotidiano. Esse indivíduo se encontra excluído da representação política, sem poder econômico, capital e cultural. Dessa forma, essa classe não tem sua narrativa considerada na sociedade e é constantemente sabotada, o que faz com que permaneça às margens da sociedade. Há também o problema da representação. Os subalternos passam a ser representados por outras pessoas que não ocupam o mesmo espaço social que eles, dando origem a falsas narrativas.

Essas narrativas são responsáveis por neutralizar ainda mais a voz do subalterno, lhe dando características que partem de uma análise superficial de suas vidas. No entanto, essas narrativas possuem grande poder de repercussão social, por partirem de teóricos renomados socialmente. Essa forma de representação do outro passa a naturalizar aquelas narrativas que são expostas em literaturas e são colocadas como pesquisas de cunho científico.

Aprofundando a ideia de representação do outro, Gayatri Spivak sustenta que a representação dos sujeitos subalternos contraria explicitamente os conceitos 
até então abordados por parte das teorias sociais. Neste ponto, Spivak mostra como o sujeito monolítico imaginado pelo pensamento universalista eurocêntrico englobaria dois sentidos de representação. O primeiro sentido é sinônimo de "falar por" (vertretung), possuindo o sentido político de representar um grupo e a suposta capacidade de conhecer a realidade do representado. Já o segundo sentido (que Spivak chama de "re-presentação") está ligado à arte e à encenação (darstellung).

Dessa maneira, para a autora a "re-presentação" dos sujeitos subalternos era o que até então estaria ocorrendo por meio da difusão de pensamentos unilaterais, sendo usados como performance, encenação ou significação, conforme seus usos na arte e filosofia. Dessa maneira, ignorar esses sentidos pode levar à substituição da fala do Outro por alguém que o significa. Em seus termos, (SPIVAK, 2010: 33). "Ao representá-los [os oprimidos e subalternos], os intelectuais representam a si mesmos como sendo transparentes"

As representações dos sujeitos subalternos apresentadas e apropriadas na literatura, na cultura e em meios de difusão de mídias sociais servem para posicionar estes sujeitos em condições de marginalidade. Pois essa falsa representação nega suas subjetividades que dão origem a suas ações. A cultura de um determinado grupo é essencial para a formação de sua identidade. No entanto as representações apresentadas à sociedade não expressam as experiências vividas, não reconhecem suas singularidades culturais e, portanto, os obriga a se enquadrar em grupos pré-determinados por uma cultura hegemônica.

Nesse contexto, as subjetividades dos indivíduos subalternos são explicitamente forjadas. Isto é, passam a ser falsamente representados por pessoas que não são subalternos, criando a ideia de uma falsa subjetividade. Pois somente a classe subalterna tem a propriedade de se auto representar, porque ela que vive em uma posição social específica e tem um olhar singular a respeito de sua localização social, que jamais pode ser perfeitamente pontuada por outra pessoa que não compartilha das mesmas experiencias de aprendizagens. Em suma, essas representações são uma das formas de manifestação da violência epistêmica e cultural que atinge a sociedade indiana diariamente.

A violência é de natureza epistemológica e fica evidente na negação de um conhecimento plausível, possível de ser erguido pelos subalternos. As ciências sociais no mundo foram colonizadas pelo pensamento europeu. Essa violência também é de natureza simbólica, com um caráter fundamentalmente cultural. Ainda assim, Spivak segue as pistas de alguns filósofos do centro. Conforme ela mesma sugere, citando Michel Foucault, a violência epistêmica está diretamente relacionada as relações de saber e de poder. Pois o poder permite a apropriação e o condicionamento de formas de pensamento, instituindo uma única vertente e aniquilando outras formas de saber por serem consideradas selvagens e primitivas.

Para compreender a aparição da violência epistêmica podemos lançar um novo olhar sobre os valores impostos pelos colonizadores sobre os povos originários. Os colonizadores europeus realizaram uma série de discursos sobre sua forma de ver essas outras sociedades e culturas. Dessa maneira, a maior parte dos teóricos coincidem em assimilar esses discursos e os reproduzir, tornando-os natural perante toda a sociedade. Não se importando em entender a essência daquele discurso, relatando que a história foi feita a partir de uma produção imparcial de conhecimento, compondo então um processo de violência epistêmica. Uma construção interessada em apresentar uma determinada representação de um objeto baseada em sua existência empírica. 
Esses discursos formulados a partir dessa observação dá origem a um olhar singular de ver o outro, que é vê-los como sub-humanos, seres selvagens. Esse paradigma é apropriado pelas ciências sociais que passam a fazer pesquisas de cunho artificial sobre esse grupo desconhecido, onde justificam através de distintas teorias que o indivíduo branco é superior sobre todas as demais. Esses conceitos são legitimados pela ciência e estão preparados para justificar qualquer exceção, gerando estruturas hegemônicas dominantes, que monopolizam o conhecimento baseado em seus conceitos que servem para a dominação. Com isso, essa violência é institucionalizada e repercute sobre toda a sociedade, sendo uma ideologia legitimadora das desigualdades sociais.

Gayatri Chakravorty Spivak (1999), introduz um conceito entendido como um processo colonial em que a Europa se estabiliza como um sujeito indeterminado que possui o poder explicativo sobre os indivíduos colonizados, que se convertem em os Outros, que esperam ser explicados por não possuírem voz e nem poder. O ponto primordial de sua crítica são as teorias ocidentais que segundo a autora: "problematizar al sujeto hacia la pregunta de cómo es representado en el discurso occidental el sujeto del tercer mundo" (SPIVAK, 1985: 260).

Visto isso, a violência epistêmica é a base das demais violências sobre os subalternos, pois ela se apropria da cultura e legitima a discriminação frente ao outro que possui diferenças consideradas indesejáveis. Ela tem o poder de se perpetuar por reaparecer de diversas formas sempre que há diferença entre os indivíduos. Com isso, a repetição de discursos é uma forma clara de efetivar a violência epistêmica em uma sociedade, pois o sujeito colonizado não terá voz para rebater essas acusações pelo fato de suas práticas não estarem vinculadas a uma ciência.

As narrativas que predominam nas sociedades colonizadas, que recebem status científico, são justamente as que naturalizam as desigualdades e negam o impacto colonial na sociedade pré-existente. Essas teorias são denominadas teorias da modernidade, pois tendem a favorecer o sistema capitalista, tornando invisível todas as formas de conhecimento que se descolam da estrutura hegemônica.

As desigualdades decorrentes dessa estrutura intelectual legitimam as mais diversas violências intelectuais e físicas que causam danos materiais a suas vítimas. Dentre essas violências criadas podemos citar o racismo que se institucionalizou perante a sociedade moderna e é a mais aparente discriminação frente a um grupo de pessoas que apresenta estereótipos diferentes do europeu. No entanto, é inegável que essa cultura de racismo tenha se originado na colonização, onde o sujeito colonizador impôs sua forma de pensar sobre as demais pessoas, tirando a capacidade de um pensamento crítico sobre suas ações que atualmente são legitimadas e presente até em instituições governamentais.

Ademais, essa ruptura epistemológica foi responsável por estabelecer um vínculo entre o capitalismo e as ciências sociais modernas. Essa união é então uma expressão da naturalização das desigualdades permanentes na atual sociedade. $\mathrm{O}$ Estado é a principal entidade capaz de mediar as relações sociais, com isso ele possui a autonomia de atuar efetivamente para combater as desigualdades que existem desde a colonização. A permanência dessas desigualdades só mostra a falta de senso crítico por parte dos teóricos sociais e por parte do próprio Estado que se apropriou de tais narrativas.

Com isso, é necessário a descolonização epistemológica: (i) Se faz necessário então conhecer o lugar de origem de tais narrativas passando a conhecer as subjetividades presentes; (ii) e relacionar os conhecimentos desenvolvidos para uma melhor compreensão de um fato apresentado, essa junção de conhecimentos será essencial para a apropriação de conhecimento de uma forma plena, por não se 
basear exclusivamente em uma narrativa; (iii) dessa maneira, os conhecimentos compreendidos irão cruzar as fronteiras do senso comum e revelarão a sociedade em sua forma mais abrangente; (iv) a agência dos sujeitos subalternos é essencial para essa nova reconceituação de saberes. A agência é definida como a fala estratégica dos sujeitos subalternos, ou seja, a sua autonomia perante a sociedade excludente na qual eles fazem parte. Além disso, a agência envolve muito mais do que a simples ideia de falar e ser ouvido. Ela abrange a questão de consciência dos sujeitos bem como sua capacidade de formar alianças.

Contudo Spivak conclui que o subalterno não pode falar. De modo que ele não possui mecanismos que efetivem sua narrativa. E como já mostrado, não se pode falar pelo subalterno, mas sim lutar contra a subalternidade. Dessa forma, os modos de representação concebidos até o momento servem para tirar a real voz do subalterno. "Aqui Spivak refere-se ao fato de a fala do subalterno e do colonizado ser sempre intermediada pela voz de outrem, que se coloca em posição de reivindicar algo em nome de um (a) outro (a)" (ALMEIDA, 2010: 14).

Para a superação desta condição subalterna é necessária a atuação do Estado na criação de um expediente em que há escuta da pluralidade de vozes que reivindicam o acesso à fala. Pois essa agência só se tornará efetivada com a ajuda de uma sociedade democrática que dê não só a liberdade de expressão. É necessário a erradicação de meios que executam uma falsa representação do subalterno e que lhe forneça métodos de autorrepresentação para que o mesmo seja ouvido. Isso fará com que ocorra a quebra de preconceitos e falsas interpretações sobre a condição subalterna no mundo.

\section{Considerações Finais}

É possível estabelecer alguns princípios que orientam as perspectivas de mudança social para Souza e Spivak: (i) a realidade é atravessa por relações de poder que não são transparentes; (ii) essas relações de poder, desde a colonização, produziram identidades subalternas na cultura; (iii) para o enfrentamento disto é preciso reconhecer as várias experiências sociais e explicitá-las como forma de perceber outras organizações e sociabilidades anticolonialistas; (iv) deve-se democratizar os lugares de decisão para que haja o maior número de vozes possível para tornar o "subalterno" em "agente" da fala. (SPIVAK, 2009; SOUZA, 2003).

O Brasil e a Índia apresentam semelhanças quanto ao processo de colonização. Com isso, esses autores buscam entender como se deu a criação social da subcidadania, por meio de uma visão crítica do pensamento social que se desenvolveu em suas respectivas sociedades.

O Estado como principal apaziguador das desigualdades não o faz, por estar diretamente ligado à elite que possui o poder de criar leis que legitimam suas ações e monopolização de recursos. O que perpetua a ação de uma única classe que consegue dominar os principais recursos políticos e econômicos das sociedades brasileira e indiana para lhes favorecerem.

Com isso, podemos observar o grau de desigualdade que existe em ambos os países. Essa desigualdade naturalizada assenta-se em mentiras que foram instituídas na cultura e literatura, vindas da escravidão. No caso particular do Brasil, esse contexto de escravidão serviu para criar uma subcidadania, que é nomeada por Jessé Souza como "A ralé brasileira" e "Os batalhadores brasileiros". Estes grupos subalternos continuam a usar sua força de trabalho como forma de subsistência, sendo assim uma mão de obra barata para empresários e latifundiários. 
Recebido em 7 de agosto de 2019.

Aceito em 30 de abril de 2020.

\section{Referências}

BHABHA, Homi. O Local da Cultura. Belo Horizonte: UFMG, 2010.

EDWARD W. Said. Cultura e Imperialismo. São Paulo: Companhia das Letras, 2011.

EDWARD W. Said. Orientalismo: o Oriente como invenção do Ocidente. São Paulo: Companhia das letras, 2007.

FIGUEIREDO, Carlos Vinícius da Silva. Estudos subalternos: uma introdução. Raído, 4 (7): 83-92, 2010.

FIGUEIREDO, Carlos Vinícius da Silva. $O$ direito ao grito: a hora do intelectual subalterno em Clarice Lispector. Dissertação (Mestrado em Letras) - Programa de Pós-Graduação em Letras, Universidade Federal de Mato Grosso do Sul, Três Lagoas, Mato Grosso do Sul, 2009.

HARDT, Michael; NEGRI, Antonio. Multidão: guerra e democracia na era do império. Tradução de Clóvis Marques. Rio de Janeiro: Multitude, 2005.

PELÚCIO, Larissa. Subalterno quem, cara pálida? Apontamentos às margens sobre pós-colonialismos, feminismos e estudos queer. Contemporânea - Revista de Sociologia da UFSCar, 2 (2): 395-418, 2012.

SOUZA, Jessé. A Construção Social da Subcidadania. Belo Horizonte: UFMG, 2006b.

SOUZA, Jessé. A Invisibilidade da Desigualdade Brasileira. Belo Horizonte: UFMG, 2006a.

SOUZA, Jessé. A Modernização Seletiva: Uma Reinterpretação do Dilema Brasileiro. Brasília: UNB, 2000.

SOUZA, Jessé. A ralé brasileira: quem é e como vive. Belo Horizonte: UFMG, 2009.

SOUZA, Jessé. A tolice da inteligência brasileira: ou como o país se deixa manipular pela elite. São Paulo: LeYa, 2015.

SOUZA, Jessé. Os batalhadores brasileiros: Nova classe média ou nova classe trabalhadora? Belo Horizonte: UFMG, 2010.

SPIVAK, Gayatri Chakravorty. "Estudios de la Subalternidad. Deconstruyendo la Historiografía”. In: MEZZADRA, Sandro (comp.). Estudios postcoloniales. Ensayos fundamentales. Madrid: Editora Traficantes de Sueños, 2008.

SPIVAK, Gayatri Chakravorty. A Critique of Postcolonial Reason. Towards a History of the Vanishing Present. Cambridge: Harevard University Press, 1999. 
SPIVAK, Gayatri Chakravorty. BBRG PRESENTS: Gayatri Chakravorty Spivak on Situating Feminism. 2013. In: UC Berkeley Events. Disponível em: https://www.youtube.com/watch?v=garPdV7U3fQ, acesso em: 02/07/2020.

SPIVAK, Gayatri Chakravorty. Culture Alive. Theory, Culture \& Society, 23 (2-3): 359-360, 2006.

SPIVAK, Gayatri Chakravorty. Entrevista 2019. In: Centro de Estudos Sociais da Universidade de Coimbra. Disponível em: https://www.youtube.com/wat ch?v=hdU5G-dunPQ, acesso em: 03/o8/2020.

SPIVAK, Gayatri Chakravorty. Pode o Subalterno Falar? Belo Horizonte: Editora UFMG, 2010.

SPIVAK, Gayatri Chakravorty. Politics of Desconstrucion: Gayatri Chakravorty Spivak and Oscar Guardiola-Rivera in Conversation. Sem data. In: Birkeck, University of London. Disponível em: https://www.youtube.com/watch?v=28zosw K4zFo, acesso em: 21/06/2020.

SPIVAK, Gayatri Chakravorty. Study, Know, Learn, Hear, Listen, Do? Humanities for social studies. 2018. In: Centro de Estudos Sociais da Universidade de Coimbra. Disponível em: https://www.youtube.com/watch?v=ZJv_WXsla_E, acesso em: 08/08/2020.

SPIVAK, Gayatri Chakravorty. The Trajectory of the Subaltern in my work. In: University of California Television (UCTV). 2004. Disponível em: https://www.youtube.com/watch?v=2ZHH4ALRFHw\&t=1886s, (1h28min). Acesso em: 13/06/2020.

TIRADO, Genara Pulido. Violencia epistémica y descolonización del conocimiento. Sociocriticism, 24 (1): 173-201, 2009. 

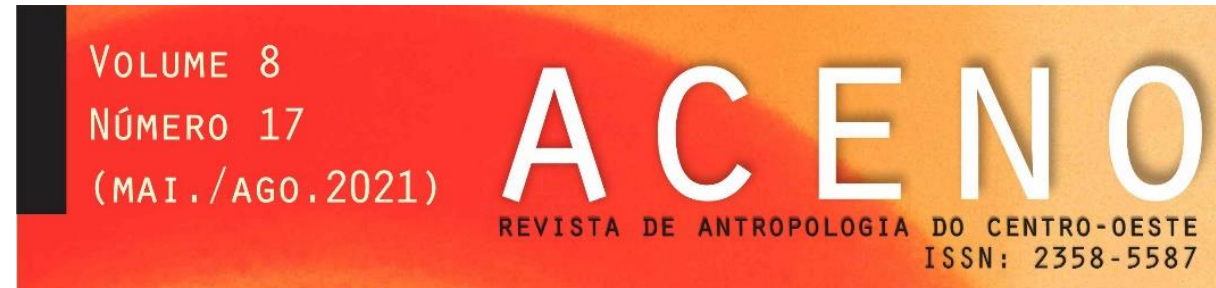

CHAMADA DE ARTIGOS

DOSSIE TEMÁTICO:

RETOMADAS E RE-EXISTÊNCIAS

INDÍGENAS, NEGRAS E QUILOMBOLAS

COORDENADORXS:

SONIA REGINA LOURENÇO (PPGAS/UFMT)

CAUÊ FRAGA MACHADO (NUPACS/UFRGS)

SANDRO JOSÉ DA SILVA (PGCS/UFES)

ste dossiê temático da ACENO tem como objeto as territorialidades

e os processos de identificação negras, quilombolas e indígenas. A

1 proposta busca chamar a atenção para processos de identificação e territorialização que forneçam perspectivas adicionais às análises

consolidadas que se dedicaram às tradições, à etnogênese e às situações de fronteiras étnicas, mais afeitos às mediações com o Estado-nação, que privilegiaram as relações políticas, agentes e agência da burocracia.

Um movimento renovado de coletivos indígenas, quilombolas e negros tem revisitado tais abordagens mediante a crítica sistemática aos padrões eurocentrados, brancos e coloniais que produziram a invisibilização sistemática do que esses movimentos consideram relevantes. Dentre essas, categorias como "retomada" e "resistência" - não apenas como reação, mas como re-existir - territorial e existencial são fundamentais quando tomadas como conceitos que descrevem diferentes vínculos entre actantes dos mais diversos modos de existência.

A proposta privilegiará a publicação de etnografias e reflexões teóricas acerca desse novo cenário no qual entes produzem reflexões cosmopolíticas e modos de agir com (ou contra) o Estado-nação de modos antes insuspeitos. Espera-se que as contribuições contemplem a diversidade regional, étnicoracial e de gênero, bem como contribuições dos povos originários e povos e comunidades tradicionais.

PRAZO FINAL Trata-se de consolidar olhares não pela via da memória ou da prova, mas DE SUBMISSÃO:

30 DE ABRIL

DE 2021 pela cosmologia e relacionalidade estendida a todos existentes, recuperando algo dado como perdido ou inexistente. Pretende-se de sublinhar identificações e territorialidades que encontram novas maneiras de se expressar, retomando terras, práticas, contato com seres, objetos, linguagens sem que essas nunca tenham sido perdidas de fato. 